\title{
LA TRANSFORMACIÓN DEL PROCESO DE DISEÑO INSTRUCCIONAL: DEL IMPRESO A LA MULTIMEDIA
}

\author{
(THE TRANSFORMATION OF THE INSTRUCTIONAL DESIGN PROCESS: FROM PRINTED \\ MATERIAL TO MULTIMEDIA)
}

Ana Luisa Mülbert

Flavia Lumi Matuzawa

Universidade do Sul de Santa Catarina, UNISUL (Brasil)

\section{RESUMEN}

Este artículo enfoca el proceso de la producción de materiales didácticos, teniendo en cuenta la perspectiva de la transformación de los tipos de materiales que son utilizados en la educación a distancia, que en el pasado tenían un fuerte énfasis en contenidos impresos y que ahora tienen un uso más intenso en materiales multimedia digitales. Se presenta el caso de la Unisul Virtual y de las lecciones aprendidas en la transformación de sus procesos de elaboración de materiales didácticos, usados en su modelo virtual de educación a distancia. La experiencia presentada muestra que los procesos de producción de materiales didácticos y la interacción de los diversos profesionales envueltos se cambian en la medida en que se modifican los tipos de resultados que son esperados en dichos procesos.

Palabras clave: diseño instruccional, objetos de aprendizaje, metodología de la enseñanza, educación a distancia.

\begin{abstract}
This article focuses on the processes of production of distance teaching materials, taking into consideration the perspective of the transformation of materials that in the past placed great emphasis on print and now place greater emphasis on digital multimedia. Referring to the case of Unisul Virtual, we describe the lessons learned during this shift in design toward a virtual model of distance education. As changes have take place in the processes of distance education materials, the patterns of interaction between the various professionals engaged in those processes have also changed.
\end{abstract}

Keywords: instructional design, multimedia learning object, teaching methodology, distance education. 
Este artigo discute o processo de design instrucional na produção de materiais didáticos e a demanda por conteúdos multimidáticos na forma de objetos de aprendizagem - ambos associados ao modelo de ensino a distância adotado pela Unisul Virtual. Este modelo de ensino, desde seu início, teve forte ênfase no uso de materiais didáticos impressos e, como forma complementar, o uso de recursos que explorassem outras mídias. Com a disseminação das tecnologias da informação e da comunicação, e ao mesmo tempo a disponibilidade cada vez mais intensiva dos alunos em fazerem uso de recursos multimidiáticos e de internet, torna-se apropriada a intensificação também do desenvolvimento de objetos de aprendizagem que vão mais além dos recursos textuais.

Neste contexto, surge o desafio de adequar os processos de design instrucional e de produção dos materiais didáticos para atender a demanda, não só por recursos didáticos impressos como também por recursos no formato multimidiático. Assim como a produção de materiais impressos conta com um fluxo de trabalho e profissionais específicos, a produção de materiais multimídia também demanda a mesma especificidade, além de processos de criação e desenvolvimento de atividades diferenciadas por parte das equipes envolvidas. A proposta deste artigo, portanto, consiste em discutir a transformação do processo de design instrucional centrado principalmente na produção de material impresso para a produção mais intensiva de conteúdos em multimídias, relatando lições aprendidas na instituição estudada. Além da fundamentação teórica, a discussão se baseará na observação dos envolvidos no processo de produção.

\section{O MODELO DE ENSINO VIRTUAL: O CASO EM ESTUDO}

A Universidade do Sul de Santa Catarina (Unisul) é uma fundação municipal de ensino, criada em 1964 no município de Tubarão, no estado de Santa Catarina, no sul do Brasil. Até o ano de 2001, a Unisul atuava apenas com oferta de educação presencial e a partir de 2002 passa a atuar também com a modalidade de ensino a distância. O crescimento da oferta nessa modalidade de ensino levou a instituição à criação do seu Campus Virtual em 2005 (Unisul Virtual), para operar na implementação de cursos superiores a distância e de disciplinas a distância nos cursos presenciais, nos moldes da legislação vigente da educação a distância. O Campus Virtual é responsável pelo planejamento, criação e implementação de cursos a distância; pela capacitação de docentes e técnicos para o uso pedagógico de metodologias de Educação a Distância, e pelo desenvolvimento de tecnologias para o ensino. 
Neste sentido, Roesler (2009) apresenta como objetivos principais do Campus Virtual: disponibilizar o conhecimento independente do tempo e da localização geográfica; facilitar a formação personalizada e continuada para a sociedade; desenvolver metodologias e serviços educacionais em favor da aprendizagem a distância, e fomentar a investigação e a inovação na sociedade do conhecimento. Para atender esses objetivos, a instituição conta com uma equipe multidisciplinar com especialistas na gestão de atividades acadêmicas, na produção de materiais didáticos, na docência mediada por tecnologias, no atendimento ao aluno, no suporte tecnológico, na logística de produção e distribuição de materiais, e no planejamento e na avaliação das diferentes atividades compõem o modelo de gestão do campus.

A oferta dos cursos a distância, desde seu princípio, foi atendida por uma metodologia fortemente baseada no uso de materiais didáticos impressos. Esse formato de material é elaborado com foco na auto-aprendizagem e no uso concomitante de um Ambiente Virtual de Aprendizagem (AVA) para efetivar a mediação pedagógica e a interação, de modo a apoiar o aluno e proporcionar-lhe o mais amplo acesso ao conhecimento.

Além desses dois elementos citados - material didático impresso e recurso online - há ainda dois outros elementos fundamentais na metodologia de ensino virtual: o sistema tutorial, por meio do qual os professores e os monitores prestam suporte pedagógico, técnico e administrativo, e as diversas vias de comunicação e interação (Unisul, 2007).

O modelo de ensino a distância adotado pela Unisul caracteriza-se, portanto, como um modelo virtual. Segundo Moran, "no modelo virtual, a orientação dos alunos é feita a distância, pela Internet ou telefone. Os alunos se reportam ao professor e ao tutor durante o semestre e geralmente se encontram presencialmente só para fazer as avaliações." Este é um modelo em que predominam as interações na Internet e os encontros presenciais são mais espaçados, porque não existem os pólos para o apoio semanal (Moran, 2009).

O modelo aqui abordado não estáfocado em uma única teoria pedagógica. Segundo Bittencourt (1999), não há teorias pedagógicas desenvolvidas especificamente para a educação a distância. Nos modelos de ensino de educação a distância faz-se uso de variados estilos e teorias pedagógicas, visando atender à diversidade dos recursos e dos alunos. O modelo de ensino virtual se desenvolve em um contexto que extrapola os métodos convencionais de ensino-aprendizagem e incorpora os ensinamentos de diversos pensadores da educação. Neste sentido, Almeida (2009) orienta que 
o ensino pela instrução e transferência de informações, centrado na atuação do professor, deixou de caracterizar a única forma de desenvolver a educação. Segundo a autora:

\begin{abstract}
"a partir dos conceitos de interação, reflexão, construção do conhecimento, aprendizagem significativa e outros, emanados das idéias de diversos pensadores como Dewey, Piaget, Vygotsky, Freire, Schön, surgiram outras abordagens educacionais e novas metodologias para o ensino centrado na aprendizagem do aluno e nas relações que ele estabelece com seu meio, englobando as pessoas e suas experiências em um contexto" (Almeida, 2009, p. 106).
\end{abstract}

Mesmo sofrendo a influência de diversas linhas do pensamento pedagógico, pode-se destacar no modelo da Unisul dois significativos focos pedagógicos que fundamentam sua atuação: o construtivismo e a andragogia.

No modelo construtivista o que uma pessoa pode aprender em determinado momento depende das possibilidades definidas por formas de pensamento, dos conhecimentos construídos anteriormente e das situações de aprendizagens vivenciadas. Dessa forma, a interação que o indivíduo mantém com o meio social, em particular nos ambientes escolares, é de fundamental importância na construção de novos conhecimentos (Unisul, 2009).

Segundo Bédard apud Bittencourt (1999), para um construtivista, o conhecimento é construído pelo aprendiz em cada uma das situações em que ele está utilizando ou experimentando. Nesta abordagem pedagógica o conhecimento provém da atividade do aprendiz e se constrói na relação de sua ação e sua experiência do mundo. É um processo educacional centrado no aluno, que estuda com autonomia a partir de estímulos propostos que visam a descoberta.

Assim, a concepção de educação a distância que fundamenta a prática pedagógica na Unisul visa, sobretudo, um processo de acompanhamento permanente e suporte aos alunos, que possibilite que este construa seus conhecimentos. Isso é feito por meio do sistema tutorial que concebe que a construção do conhecimento não se dá de forma linear, mas que ao mesmo tempo deixa claro os caminhos que o aluno pode seguir a partir de uma coletânea de recursos didáticos e do suporte comunicacional desenvolvido pela instituição (Unisul, 2009).

Como a metodologia de ensino visa atender a um público de indivíduos maduros e em sua maioria já inseridos no mundo do trabalho, o modelo de ensino utiliza também como referência a andragogia, na qual o processo de ensino é construído 
contemplando a autonomia e a auto-gestão do conhecimento como pressupostos básicos para o ensinar e para o aprender. Knowles et al. (1997) afirma que a autonomia significa assumir a aprendizagem através das metas e propósitos da mesma. Essa atitude leva a uma mudança externa de consciência, no qual o estudante vê o conhecimento como contextual e livre de perguntas do que foi aprendido. A andragogia oportuniza ao aluno adulto participar de sua própria aprendizagem por meio de intervenções no planejamento ou na realização das atividades propostas pelo professor (Unisul, 2009).

Segundo Almeida (2009), a proposta de aprender por si mesmo foi enfatizada por Carl Rogers, que destacou que não se pode ensinar diretamente outra pessoa, e sim facilitar sua aprendizagem. No entanto, apenas colocar o aluno diante de informações, problemas e objetos de conhecimento pode não ser suficiente para envolvê-lo e despertar sua motivação pela aprendizagem autônoma. Neste contexto, emerge o conceito de aprendizagem significativa que na perspectiva de Vygotsky se refere à experiência pessoalmente significativa que emerge no contexto e orienta o desenvolvimento, podendo trazer efetiva contribuição se utilizado como instrumento de reconhecimento do desenvolvimento do aprendiz e daquilo que é significativo para ele.

Assim, o modelo de ensino aqui em estudo propõe oferta de materiais didáticos, acompanhado por um sistema de atendimento de professores e monitores em ambiente virtual, que visa dar suporte à interatividade necessária para o compartilhamento de experiências e conhecimentos.

\section{O DESIGN DOS MATERIAIS DIDÁtICOS: PROCESSO EM TRANSFORMAÇÃO}

O conteúdo instrucional precisa estar adequado à metodologia de ensino aplicada e também ao perfil do seu público-alvo. Neste sentido, para motivar o estudo autônomo, todos os materiais são elaborados a partir da perspectiva do trabalho realizado pelo designer instrucional que propicia o estudo autônomo e a distância, além de promover a utilização das tecnologias de informação e comunicação como componentes mediadores da aprendizagem. Além do designer instrucional, outros especialistas atuam na produção dos materiais didáticos. Esses especialistas são profissionais de diversas áreas do conhecimento que contribuem na produção do conteúdo didático, exemplo deles são: os professores especialistas, designers gráficos, designers instrucionais, pedagogos, psicólogos etc. Todos os profissionais seguem uma linha de trabalho baseado principalmente em: 
- desenho instrucional baseado em correntes de andragogia e psicologia que privilegiam o aluno como agente na construção do conhecimento;

- conteúdos e atividades preparados com ênfase no "aprender a aprender" e na auto-aprendizagem;

- utilização e/ou desenvolvimento de tecnologias apropriadas ao perfil dos alunos;

- utilização das tecnologias de informação e comunicação como instrumentos mediadores da aprendizagem (Unisul, 2007).

Considerando que o material impresso demarca com bastante precisão o modelo pedagógico em estudo, o processo de design instrucional sempre esteve direcionado às etapas de produção de maneira bastante especializada para a produção final deste recurso didático. Para este tipo de mídia, a instituição conta com um fluxo de produção já consolidado. O designer instrucional participa do início ao fim do processo interagindo com coordenadores de cursos, professores conteudistas e toda equipe interna de produção: designers visuais, revisores ortográficos e logística.

Este trabalho integrado é imprescindível e necessário quando trabalhando na produção de materiais a alunos envolvidos em uma modalidade a distância. A precisão das informações e sua corretude na abordagem e na didática apresentada são fatores de sucesso em um curso a distância.

Morrison (2004) destaca que a equipe multidisciplinar que trabalha na produção do material deve buscar integrar saberes, necessidades, interesses objetivos, conteúdos, estratégias, mídias (ferramentas) e avaliações, em um roteiro a partir do qual se desenvolve um curso. Gutierrez e Prieto (1994) acreditam no conceito de co-responsabilidade não havendo pessoas trabalhando separadamente, sem trocar idéias. O processo de produção, portanto, apóia-se no trabalho em equipe. 


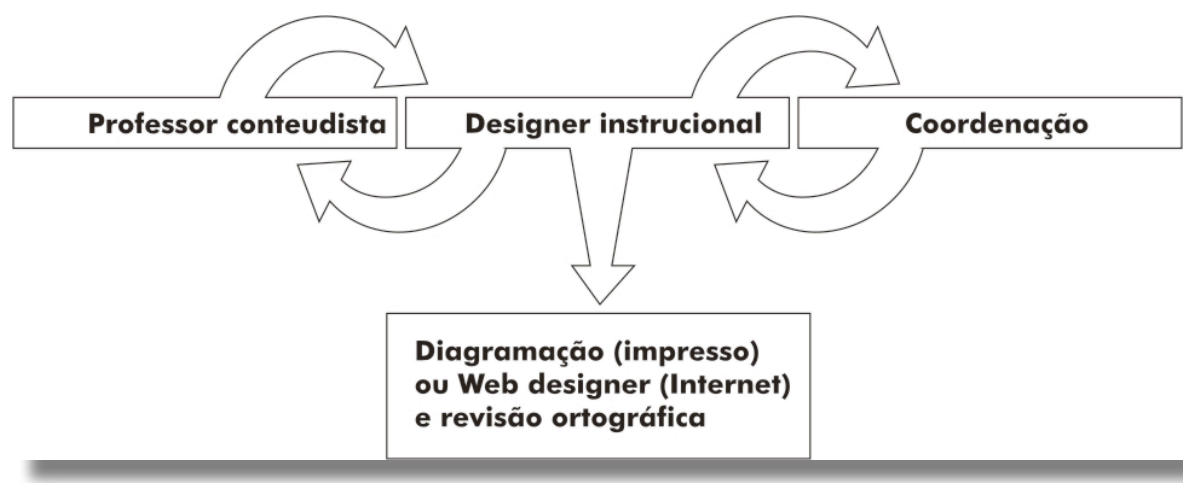

Figura 1. Processo comunicacional no desenvolvimento de materiais didáticos na Unisul Virtual Fonte: Unisul (2005, p. 16)

Conforme ilustrado na Figura 1, o designer instrucional acaba por centralizar as ações, pois está em contato direto tanto com o professor especialista no assunto como com as demais equipes envolvidas na produção dos materiais. Ele é responsável por envolver o suporte necessário de pessoas e coordenar o trabalho preparatório entre artistas gráficos, roteiristas, equipe de produção de vídeo, fotógrafo, programadores, design de multimídia, administradores de redes, etc. (Morrison, 2004, p. 350). Mesmo assim, apesar de sua integração, o foco principal do designer instrucional é a análise do conteúdo e, juntamente com o design gráfico, precisa estudar maneiras ideais de apresentar o conteúdo de maneira a contemplar a aprendizagem.

Neste momento o enfoque do designer instrucional passa também por um processo de elaboração do texto e adequação da linguagem utilizada nos conteúdos para uma forma apropriada à modalidade do ensino a distância. Cabe salientar que cada mídia utilizada, demanda uma linguagem e uma forma visual diferenciada. Essas e outras questões são definidas no projeto pedagógico do curso, que norteia o desenvolvimento de todo o processo.

No material didático impresso, a linguagem precisa ser acessível ao públicoalvo e abordar os conteúdos de maneira clara e pontual. Para Sartori e Roesler (2005, p. 78), a redação do texto acontece com o exercício de um "suposto diálogo entre autor e os leitores reativos, que interpretam, questionam, sugerem e criam a partir das discussões que ele provoca". E é este o objetivo do texto para o material didático: o cuidado em estabelecer um diálogo entre o professor e o aluno instigando questionamentos e reflexões acerca do conteúdo apresentado. Essa atividade acontece por meio de textos e outros materiais disponibilizados aos alunos e está 
totalmente ligada ao trabalho de design instrucional, visto que o objetivo é sempre buscar a melhor forma de apresentar e estruturar o conteúdo. Isso acontece porque pelo fato da presença física não acontecer, os conteúdos devem ser apresentados de maneira diferente do ensino presencial, pois o material deve, por si só, desencadear um processo educativo.

Alguns resultados de pesquisas aplicadas junto aos alunos que ingressam nos cursos a distância já começam a delinear novas perspectivas, tendo em vista o desenvolvimento tecnológico: a velocidade de acesso aos alunos passa para o contexto de banda larga e da mobilidade, havendo necessidade do uso de recursos mais dinâmicos para possibilitar maior interatividade entre os agentes envolvidos. Com a rápida mudança no perfil dos alunos é inevitável um público cada vez mais ávido por soluções online, viabilizados por meio de recursos audiovisuais e hipermidiáticos. Cabe ao designer instrucional entender e dominar como se dá sua atuação no desenvolvimento deste tipo de conteúdo (Matuzawa e Martins Filho, 2009).

Se antes não era possível avançar muito no uso de recursos tecnológicos sem excluir alunos que não possuíam recursos computacionais avançados, hoje, com a disseminação das tecnologias, os próprios alunos já manifestam seu interesse por esses recursos. Na Unisul, os resultados da avaliação institucional realizada com os alunos evidenciam essa demanda.

Assim, visando a melhoria de serviços prestados e materiais produzidos, a Unisul Virtual vem articulando-se para, em grupos representativos, discutir pontos-chave que venham a contribuir ao aperfeiçoamento do modelo pedagógico vigente e dos processos de trabalho dele decorrentes. Cada melhoria ou novo projeto é discutido em grupo, levantando alternativas que venham atender às necessidades e assim, redefine-se o fluxo e elabora-se os documentos referentes ao trabalho divulgando as novas informações a todo o grupo. Assim como na produção de material didático impresso, o designer instrucional, precisa entender e prever como o conteúdo se comportará no formato digital.

Aqui começa um novo desafio em sua formação e conhecimentos necessários, porque o designer instrucional precisa também conhecer o conceito de ciberespaço e suas implicações ao trabalhar com conteúdos digitais (Echeverría, 1999). Além de prever navegações entre links, apresentar uma linguagem diferenciada para o ambiente multimídia e usar recursos gráficos e de áudio, o designer instrucional precisa promover a compreensão e a aprendizagem do aluno (Mayer, 2009). 
Novamente o trabalho integrado do design instrucional com equipes específicas, como o design visual, por exemplo, retoma sua configuração, desta vez com critérios diferenciados e adaptados à natureza da nova mídia.

Implementar na prática o desenvolvimento de conteúdo didático requer planejamento adequado para fragmentar um conteúdo específico ao ponto de não fazê-lo perder o significado. Se por um lado, o desafio na produção de material impresso está em propor um conteúdo didático em que haja sequenciação do conteúdo levando a uma reflexão significativa dos assuntos apresentados aos alunos, o desafio para a produção multimídia, caminha em direção oposta: o foco está em procurar por fragmentos, que constituam uma epítome, isto é, um elemento básico que sirva de ponto de partida - e não algo sem sentido em si mesmo. (Tarouco et al. 2006).

Ao mudar o foco da produção de materiais, muda-se os processos de trabalho dos profissionais envolvidos neste processo. Muda-se também o próprio processo de trabalho, sobretudo, dos designers e conteudistas.

\section{UMA NOVA RELAÇÃO ENTRE CONTEUDISTA E O DESIGNER INSTRUCIONAL}

No caso em estudo, uma das mais significativas mudanças observadas em relação aos processos de produção de materiais didáticos em multimídia está relacionada à concepção e delineamento desses materiais. Os materiais impressos possuem uma estrutura previamente definida e prevista pela metodologia de trabalho. Por outro lado, os materiais em multimídia não apresentam a mesma possibilidade de padronização já que devem se adequar ao contexto do conteúdo que abordam.

No desenvolvimento dos materiais impressos o professor conteudista, antes de produzir o material, passa por processo de capacitação com a finalidade de alinhar sua ação de criação do material à metodologia de ensino virtual e ao padrão dos materiais produzidos pela instituição. Entre outras atividades, essa capacitação visa destacar ao conteudista as características desse material quanto à sua linguagem e estrutura (objetivos, unidades, atividades de aprendizagem, etc). Esse foi o mecanismo encontrado pela instituição para facilitar o design dos materiais impressos e potencializar a interação entre o designer instrucional e o conteudista.

Como os materiais impressos das diferentes disciplinas e cursos desenvolvidos têm uma estrutura muito similar, pode-se estabelecer um processo de trabalho 
composto por etapas previamente definidas em um fluxo de trabalho previsível. Os materiais multimidiáticos, por outro lado, diferem muito da lógica dos livros impressos, haja visto que eles podem assumir inúmeras formas diferentes. Podem manipular inúmeras combinações de recursos de áudio e imagens, que combinados entre si e com textos complementares podem trazer inúmeras possibilidades que fogem dos conteúdos padronizados dos materiais impressos.

Essa mudança na natureza do resultado esperado da criação de materiais didáticos tem forte impacto sobre a produção dos materiais, exigindo de toda a equipe envolvida novas habilidades e novas formas de trabalhar. Nos materiais impressos cabe ao designer instrucional capacitar o professor conteudista sobre a estrutura de material esperada e dar suporte ao seu desenvolvimento à medida que este o desenvolve. No caso dos recursos multimidiáticos, essa dinâmica se altera. O desafio inicia com a necessidade de conceber em conjunto qual será o recurso a ser desenvolvido e seus devidos contornos.

Segundo Moreira (2009), os autores dos materiais didáticos "são os profissionais que desenvolvem o conteúdo, selecionando e reunindo materiais, organizando e propondo dinâmicas, estratégias e recursos pedagógicos a serem desenvolvidos". Entretanto, os conteudistas não são especialistas no uso das diferentes linguagens das diferentes mídias. Dessa forma, na prática observa-se que apresentam certa limitação quanto à sua capacidade de propor o uso das multimídias na abordagem do conteúdo. Sua especialidade está no domínio do conteúdo e não das mídias que podem viabilizá-los. Essa limitação não se torna tão evidente quando o formato do material a ser desenvolvido (os livros impressos) era facilmente previsto.

Para Moreira (2009), o designer instrucional é em geral um profissional multidisciplinar que tem, entre outras funções, a responsabilidade de propor a adaptação dos conteúdos em materiais digitais adequando-os à mídia a ser utilizada. Entretanto, como este não tem o domínio do conhecimento desenvolvido no material, não tem condições de sozinho propor em definitivo quais os contornos do objeto de aprendizagem a ser desenvolvido para cada diferente conteúdo.

Neste caso, configura-se a necessidade ainda maior de intensificar a interação entre conteudista, designer instrucional e designer visual. É por meio desta interação que os designers visual e instrucional, por meio de estímulos e questionamentos ao conteudista, podem investigar a natureza do conteúdo e as possibilidades de explorar novas linguagens e mídias. Ao conteudista cabe expandir sua visão sobre as formas tradicionais de abordar os conteúdos de seu domínio e aos poucos passar a 
agir de modo mais ativo na proposição dos objetos de aprendizagem em multimídia. À toda equipe fica a responsabilidade de desenvolver materiais cuja instrução seja eficiente e que trabalhe em harmonia com o processo de aprendizagem humana. Sweller et all. (2006) afirma que ambientes instrucionais eficientes levam a uma melhor aprendizagem, uma aprendizagem mais rápida, ou ambas porque eles fazem o melhor uso da capacidade cognitiva humana.

Diante dessa intensa interação, o processo de criação dos conteúdos passa a ocorrer de modo mais simultâneo e conjunto entre designers e conteudista. Juntos poderão decidir quais as mídias e estratégias de seu uso mais adequadas ao conteúdo proposto. No processo de elaboração dos materiais impressos, o trabalho conjunto se dá em ocasiões mais pontuais, onde cada um tem seu próprio momento de intervir. Ainda neste fluxo de trabalho, o próprio designer visual atua em momento posterior ao iniciado pelo conteudista e designer instrucional. Na dinâmica da produção multimídia, o designer instrucional passa a ser também um educador, que oferta estímulos e gera nova aprendizagem ao professor conteudista - trabalho este muito entrelaçado com as possibilidades midiáticas apresentadas pelo designer visual.

É importante destacar que, para cada conteudista, pode-se encontrar maior ou menor dificuldade em explorar novas mídias. Acredita-se que, à medida que o uso de objetos de aprendizagem em multimídia se tornam cada vez mais corriqueiros, os próprios conteudistas passam a incorporar o domínio das diferentes linguagens e passam a compreender melhor o potencial de seu uso.

Assim, evidencia-se que da mudança na natureza dos resultados esperados do processo de produção emerge a necessidade de uma nova forma de pensar que, por sua vez, impacta nos processos de trabalho que levam à construção dos materiais didáticos.

\section{CONSIDERAÇÕES FINAIS}

A emergência de novas tecnologias educacionais tem possibilitado inúmeras novas formas de abordagem de educação. A educação em modelos virtuais de aprendizagem já é, em si mesma, resultado disso. As instituições de educação a distancia, e em especial a que aqui é objeto de estudo, reconhecem a necessidade de incorporar cada vez mais objetos de aprendizagem que explorem toda a potencialidade das tecnologias da informação e da comunicação. Ao conceber modelos de ensino que pressupõem estruturas de apoio que exigem intensa preparação antes da entrega dos materiais de estudo, deve-se ter a preocupação de criar estruturas capazes de desenvolver esses materiais a contento. 
Encontrar o equilíbrio na forma de apresentar o conteúdo e no conceito a ser transmitido é um grande desafio, pois trabalha-se com estímulos que vão além da visão (no caso a leitura de um texto estático, para o caso de ser material impresso): audição (narração e efeitos sonoros de modo geral), interação com o conteúdo (o usuário pode escolher a opção que deseja aprofundar seu estudo), leitura textual e animação (recursos gráficos animados).

Buscou-se demonstrar neste artigo que a mudança nos tipos de materiais didáticos utilizados na educação exige também novas competências e novos processos de trabalho. Se mudam os objetos do aprender, muda também a lógica que os cria, muda a forma de perceber e conceber os conteúdos didáticos e, consequentemente, mudam também as habilidades desejáveis entre aqueles que participam de seu processo de criação.

\section{REFERÊNCIAS BIBLIOGRÁFICAS}

Almeida, M. E. B. (2009). As teorias principais da andragogia e da heutagogia. In: Litto, F. M.; Formiga, M. (org). Educação a distância: estado da arte. São Paulo: Pearson.

Bittencourt, D. F. (1999). (Dissertação). A construção de um modelo de curso "lato sensu" via internet. Programa de PósGraduação em Engenharia de Produção Universidade Federal de Santa Catarina. [en línea] Disponível em: http://www. eps.ufsc.br/dissertag9/denia/. (consulta 2009: 10 de septiembre).

Echeverría, J. (1999). Os senhores do ar: Telépolis e o terceiro meio. Barcelona.

Filatro, A. (2008). Design Instrucional na prática. São Paulo: Pearson Education do Brasil.

França, G. (2008). O design instrucional na Educação a Distância: John Dewey como uma referência metodológica. São Paulo: Ed. Esfera.

Gomez, M. V. (2004). Educação em rede: uma visão emancipadora. São Paulo: Instituto Paulo Freire.

Gutierrez, F.; Prieto, D. (1994). A mediação pedagógica: educação a distância alternativa. Campinas, SP: Papirus.

Knowles, M. S.; Holton, E. F.; Swanson, R. A. (1997). The adult Learner: the Definitive
Classic in Adult Education and Human Resource Development. Houston, TX: Gulf Publishing.

Maia, C.; Mattar, J. (2007). ABC da EaD: a educação a distância hoje. 1. ed. São Paulo: Prentice Hall.

Matuzawa, F. L.; Martins Filho, V. (2009). Pós-Graduação: especialização em EAD: design instrucional. Colaboração Vanessa Andrade. Ribeirão Preto: Faculdade Interativa COC.

Mayer, R. E. (2009). Multimedia learning. Cambridge.

Moran, J. M. (2009). Modelos de ensino superior a distância no Brasil. Revista Acadêmica Eletrônica Sumaré. [en línea] Disponível em: http://www. sumare.edu.br/raes/edicoes/edo1/ raesedo1 artigo06.pdf (consulta 2009, 10 de septiembre).

Moreira, M. da G. (2009). A composição e o funcionamento da equipe de produção. In: Litto, F. M.; Formiga, M. (org.). Educação a distância: estado da arte. São Paulo: Pearson.

Morrison, G. R.; Ross, S. M.; Kemp, J. E. (2004). Designing effective instruction. 4 ed. John Wiley \& Sons, Inc. 
Pandini, C.; Guedes, E.; Matuzawa, F. (2006). Vídeo digital na EaD: a integração do design instrucional e gráfico no desenvolvimento de uma metodologia para o modelo pedagógico da UnisulVirtual. In: Anais Conference ICBL2007 May 07 - 09, 2006. Florianopolis, Brazil.

Roesler, J.(2009). Comunicação, Socialidade e Educação on-line. Tese (Doutorado em Comunicação Social). Pontifícia Universidade Católica do Rio Grande do Sul. Porto Alegre. [en línea] Disponível em: http://tede.pucrs.br/tde busca/ arquivo.php? codArquivo $=1694$. (consulta 2009, 1 de septiembre).

Sartori, A.; Roesler, J. (2005). Educação Superior a Distância: gestão de aprendizagem e da produção de materiais didáticos impressos e on-line. Tubarão: Ed. Unisul.

Tarouco, L. M. R.; Konrath, M. L. P.; Carvalho, M. J. S.; Avila, B. G. (2006). Formação de professores para produção e uso de objetos de aprendizagem. In: Novas Tecnologias na Educação, 4 (1).
Julho, 2006. [en línea] Disponível em: http://www.cinted.ufrgs.br/renote/ jul2006/artigosrenote/a20 21173.pdf (consulta 2009, 20 de septiembre).

Thompson, N. (2008). Why ID? The Benefits of Instructional Design Models, Vol. 7 (6): February 15, 2001. [en línea] Disponível em http://www.uwsa.edu/ ttt/articles/thompson.htm (consulta 2008, 24 de octubre).

UnisulVirtual. (2005). Guia do professor conteudista. Palhoça: Unisul Virtual.

UnisulVirtual. (2007). Equipe DidáticoPedagógica. Formação para Professor Tutor: Metodologia UnisulVirtual. Palhoça: Unisul Virtual.

Unisul. (2007). Guia para designer instrucional. Palhoça: Unisul Virtual.

Unisul Virtual. (2009). Organização didático-pedagógica da Unisul Virtual. Palhoça.

Willis, B. (1993). Instructional development for distance education. Distance Education: A practical guide. Englewood Cliffs, NJ: Educational Technology Publications. 


\section{PERFIL ACADÊMICO E PROFISSIONAL DOS AUTORES}

Ana Luíza Mülbert, Bacharel em Ciência da Computação, Pedagogia e Mestre em Administração. Professora e Pesquisadora no Núcleo de Estudos de Ensino da Distância da Universidade do Sul de Santa Catarina (UNISUL). Coordenadora do curso superior de Gestão da Tecnologia da Informação na modalidade a distância.

Correio eletrônico: amulbert@gmail.com

Flavia Lumi Matuzawa, Bacharel em Ciências da Computação e mestre em Engenharia de Produção na área de Mídia e Conhecimento pela Universidade Federal de Santa Catarina-UFSC (Brasil). É pesquisadora no Núcleo de Estudos de Ensino da Distância da Universidade do Sul de Santa Catarina (UNISUL), Designer Instrucional na Unisul Virtual e desenvolve materiais didáticos impressos e objeto de aprendizagem multimídia. Contribuiu in loco na implementação de centro de Educação a Distância do Instituto Politécnico de Leiria (Portugal). É pesquisadora do Projeto Alfa/Miforcal (América Latina - Formação Acadêmica) coordenado pela Universidade Ca' Foscari de Veneza (Itália) e pesquisadora do Projeto Redes - coordenado pela CIAFIC/CONICET (Argentina), com foco sobre a produção de objetos de aprendizagem multimídia.

Correio eletrônico: flavialumi@yahoo.com.br

DIRECCIÓN DE LÃS AUTORAS:

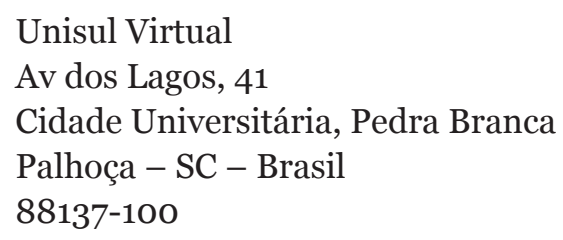

Fecha de recepción del artículo: 11/01/10

Fecha de aceptación del artículo: 16/09/10 